\title{
Possibilities of using interlayers during diffusion welding of Ti Gr2 and AISI 316L
}

\author{
Jaromir Moravec ${ }^{1, *}$, Iva Novakova $^{1}$, Tomasz $\mathrm{Kik}^{2}$ \\ ${ }^{1}$ Technical University of Liberec. Studentská 2, 46117 Liberec 1. Czech Republic \\ ${ }^{2}$ Silesian University of Technology, Welding Department, Konarskiego 18A, Gliwice, Poland
}

\begin{abstract}
Joining of materials with different physical and mechanical properties is always very problematic. As one of the possibilities, there can be used method of joint creation in solid state - e.g. by the diffusion welding. With this method it is possible to joint very different materials - even metals with non-metals. Despite the unquestionable advantages of this method, there is necessary to take into account also its limits. Among of them, there is creation of brittle intermetallic phases on the boundary of materials. This occurs e.g. at creation heterogeneous joints between titanium and highly-alloyed austenitic steel. The major aim of this paper is to describe how it is possible to eliminate brittle intermetallic phases created on boundary between Ti Grade 2 and AISI 316L steel by using metal interlayers.
\end{abstract}

Keywords: Diffusion Welding, Interlayers, Titanium Grade 2, AISI 316L steel, Heterogeneous Welds

\section{Introduction}

Diffusion welding is fairly quite a new technology in the research field. It has numerous applications in distinct areas such as aerospace, nuclear, automotive, electronics and sensor industries. This has led to increasing attention for the researcher to develop new and advanced materials.

Diffusion, as every transport effect, can be described by two aspects. Phenomenological diffusion theory deals with the overall balance of transport process in solid substance undertaken in the given conditions. This theory takes into account only macroscopic perspective. Microscopic perspective is considered in the atomic diffusion theory. This theory respects internal composition of material including crystal lattice interferences. In the case of non-existing motive power on atoms, their jumps are random. However these jumps occur in specific crystallographic equivalent directions.

The diffusion process can be divided into two types: self-diffusion and hetero-diffusion. Self-diffusion takes place in pure metal. During self-diffusion, atoms migrate randomly throughout the crystal lattice. Due to the random movement of atoms in the grid, concentration gradient arises in crystal lattice but mass of pure metal isn't changed. Concentration gradient can be expressed by Fick's laws when the Fick's first law (eq. 1)

\footnotetext{
* Corresponding author: jaromir.moravec@tul.cz

Reviewers: August Sládek, Ivo Hlavatý
} 
indicates a variation of concentration in the $\mathrm{x}$-direction per unit of time. The diffusion flux $\mathrm{J}$ $\left[\mathrm{mol} \cdot \mathrm{m}^{-2} \cdot \mathrm{s}^{-1}\right]$ of atoms per unit time and unit area in the direction of the $\mathrm{x}$-axis is proportional to the concentration gradient. Mathematically, it is expressed as:

$$
J=-D \cdot\left(\frac{\partial C}{\partial x}\right)
$$

Where $\mathrm{D}\left[\mathrm{m}^{2} \cdot \mathrm{s}^{-1}\right]$ is diffusion coefficient, $\mathrm{C}\left[\mathrm{mol} \cdot \mathrm{m}^{-3}\right]$ is concentration of elements, $\mathrm{x}$ $[\mathrm{m}]$ is diffusion direction and $\mathrm{t}[\mathrm{s}]$ is time. In most practical cases, diffusion processes are non-stationary ones, because diffusion processes are changing over time. It can be deduced as relation called Fick's second law (eq. 2). In mathematical form, it is represented as:

$$
\frac{\partial C}{\partial t}=\frac{\partial}{\partial x}\left(D \cdot \frac{\partial C}{\partial x}\right)=D \cdot \frac{\partial^{2} C}{\partial x^{2}}
$$

Hetero-diffusion occurs between two phases of the material. It is more complex phenomenon and possible only if atom has sufficient amount of energy to displace from one position to another one. When the atom moves in the grid, it creates a hole or vacancy in its node.[1,2]

\section{Possibilities to joint Ti Gr2 and AISI 316L without interlayers}

There are several methods how to create heterogeneous joints between titanium and highlyalloyed stainless steel. As the $1^{\text {st }}$ possibility there is fusion welding, because both materials have similar magnitudes of melting temperatures. For own jointing can be used e.g. TIG method (however with precise shielding of weld pool), eventually electron-beam welding. However, in both cases takes place immixture of both materials at creation different intermetallic compounds (IMCs) in the weld metal. Mostly there are phases as $\mathrm{TiFe}$ and $\mathrm{TiFe}_{2}$ that are typically of their high hardness and brittleness [3]. So as the aim of the welding process there is tendency to apply processes, which can eliminate quantity of areas, where are these IMCs created. Diffusion welding seems to be quite suitable possibility welding technology, because area of mutual diffusion of elements varies here just within the few tens of micrometers.

Nevertheless, even there is very narrow diffusion area, IMCs are also created within it and hence there is important increase of hardness values as can be seen from Fig. 1 (measurement of hardness HV0.02). Due to that, ductility of created joint is very low. So as a solution, there is utilization of interlayers from elements, which don't create hard and brittle IMCs with titanium. Their purpose is to create with both materials diffusion joint, but also to prevent mutual diffusion of $\mathrm{Ti}$ and $\mathrm{Fe}$ at the same time.

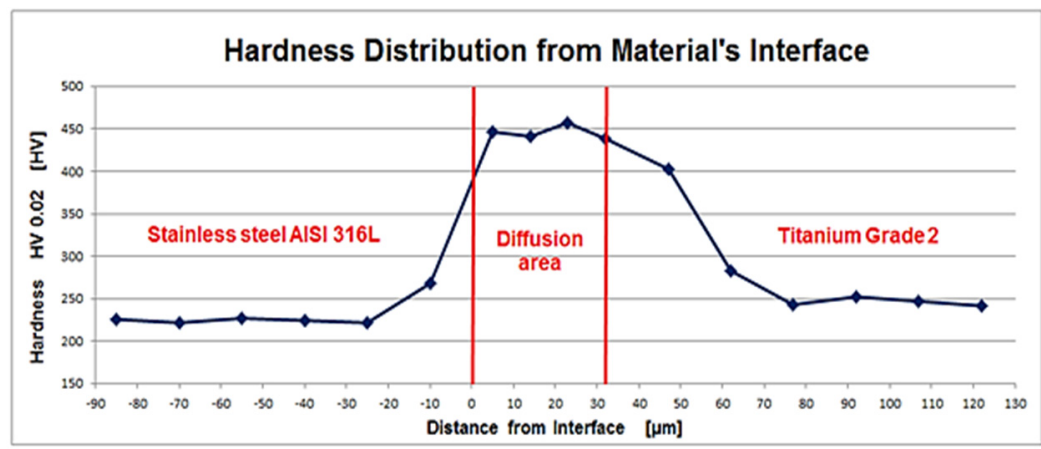

Fig. 1 Measurement of micro-hardness HV 0.02 over the diffusion area [3] 


\section{Possibilities to joint Ti Gr2 and AISI 316L by the interlayers}

Based upon the performed recherché there was determined that for diffusion bonding of titanium and highly alloyed austenitic steels it is possible to use $\mathrm{Ni}, \mathrm{Ag}$ or eventually $\mathrm{Cu}$ interlayer. Together with titanium, these elements create compounds that are tough enough and thus suitable to remove abnormal brittleness in the joint area. In all cases monitored in recherché was for the diffusion welding used thermal-mechanical simulator Gleeble and that is why the same device was also used for the experimental verification of the individual interlayers properties.

As the first interlayer used for the bonding there was used the Nickel one. From the research paper of Chatterjee and Kundu [4], it is investigated that the diffusion bonding between commercially pure Ti Gr 2 and AISI 304 steel with the help of Ni interlayer reveals good result on final welded joint in view of ductility. They used bonding temperature within range from 850 up to $950^{\circ} \mathrm{C}$, but applied pressure wasn't mentioned in the article. Also FangLi Wang [5] and his colleagues used diffusion bonding between commercially pure Ti Gr 2 and AISI 304 steel with the help of $\mathrm{Ni}$ interlayer. They used impulse pressuring in range from 8 up to $20 \mathrm{MPa}$ with duration of 60 up to $150 \mathrm{sec}$ at temperature $850^{\circ} \mathrm{C}$.

During the experimental verification of $\mathrm{Ni}$ interlayer application suitability was determined that maximal available pressure at temperature $870^{\circ} \mathrm{C}$ is $3.2 \mathrm{MPa}$. Then there is very rapid deformation on the side of pure titanium, which is unacceptable from the industrial utilization point of view. At temperature $900^{\circ} \mathrm{C}$ is maximal available pressure lower than 1 $\mathrm{MPa}$ and at temperature $850^{\circ} \mathrm{C}$ must be pressure below $6.5 \mathrm{MPa}$.

At diffusion welding in vacuum and using device Gleeble 3500 there was determined that at temperature $870^{\circ} \mathrm{C}$ and pressure $3 \mathrm{MPa}$ is not bonding between $\mathrm{Ni}$ interlayer on one side and $\mathrm{Ti}+\mathrm{AISI} 316 \mathrm{~L}$ on the other side sufficient enough - even after keeping holding time 50 min at used temperature. Magnitude of deformation for these samples after 50 min achieved only $0.182 \mathrm{~mm}$. Moreover, there was experimentally determined that diffusion bonding of sufficient quality with $\mathrm{Ni}$ interlayer is created not below temperature $1050^{\circ} \mathrm{C}$, pressure 4.5 $\mathrm{MPa}$ and holding time $20 \mathrm{~min}$. Nevertheless, this was possible to be verified only for steel AISI 316L, which can resist such temperature and pressure without any problems. The total deformation of sample under these parameters didn't exceed $0.2 \mathrm{~mm}$.

By utilization of the impulse pressuring diffusion welding acc. to Fang-Li Wang [5] parameters it is also possible to achieve diffusion bonding of high quality. However, it is necessary to take into account deformation over $15 \%$ on the side of pure titanium, which is more than impracticable from the light of industrial utilization.

As the second interlayer used for the bonding Ti Gr2 and AISI 316L there was used the Ag interlayer. From the research paper of Yongqiang Deng and his colleagues [6] it is reported that using of $\mathrm{Ag}$ interlayer exhibits good result in light of micro-hardness distribution of bonded joint. Yongqiang Deng used device Gleeble and experiments were performed at temperatures $825,850,870^{\circ} \mathrm{C}$ and pressure $6 \mathrm{MPa}$. At experimental verification of $\mathrm{Ag}$ interlayer application suitability, there was carried out experiment at temperature $850^{\circ} \mathrm{C}$, because at temperature $875^{\circ} \mathrm{C}$ and pressure $6 \mathrm{MPa}$ would be again presented a very intense deformation of Ti Gr2.

Fig. 2 reveals SEM image with EDS scanning line of sample. Several distinct layers from left to right side (Ti/Ti s.s/TiAg/Ag/SS) were observed. Titanium solid solution (abb. Ti s.s) $19.55 \mu \mathrm{m}$, Ti-Ag IMC (TiAg) $28.33 \mu \mathrm{m}$ and Ag interlayer $82.62 \mu \mathrm{m}$ thicknesses were measured in the joint interface. From EDS analysis is evident that during holding time on temperature there occurs very intense diffusion between Ti and Ag. However, on the side of AISI 316L is diffusion minimal. Yongqiang Deng states that acc. to $\mathrm{Ag}-\mathrm{Fe} / \mathrm{Cr} / \mathrm{Ni}$ binary diagrams [7], Ag cannot form IMCs with the main elements in SS. That is true, but there should be also state that solubility of $\mathrm{Ag}$ in $\mathrm{Fe}, \mathrm{Cr}$ and $\mathrm{Ni}$ in solid state is almost on zero value. So it means that diffusion processes probably will not take place, which is also 
confirmed by result of EDS analysis. Acc. to binary diagram Ag-Fe is solubility of Ag in iron at temperature $850^{\circ} \mathrm{C}$ lower than $0.01 \mathrm{wt} \%$. Thus the bonding between surfaces is created only due to adhesion.

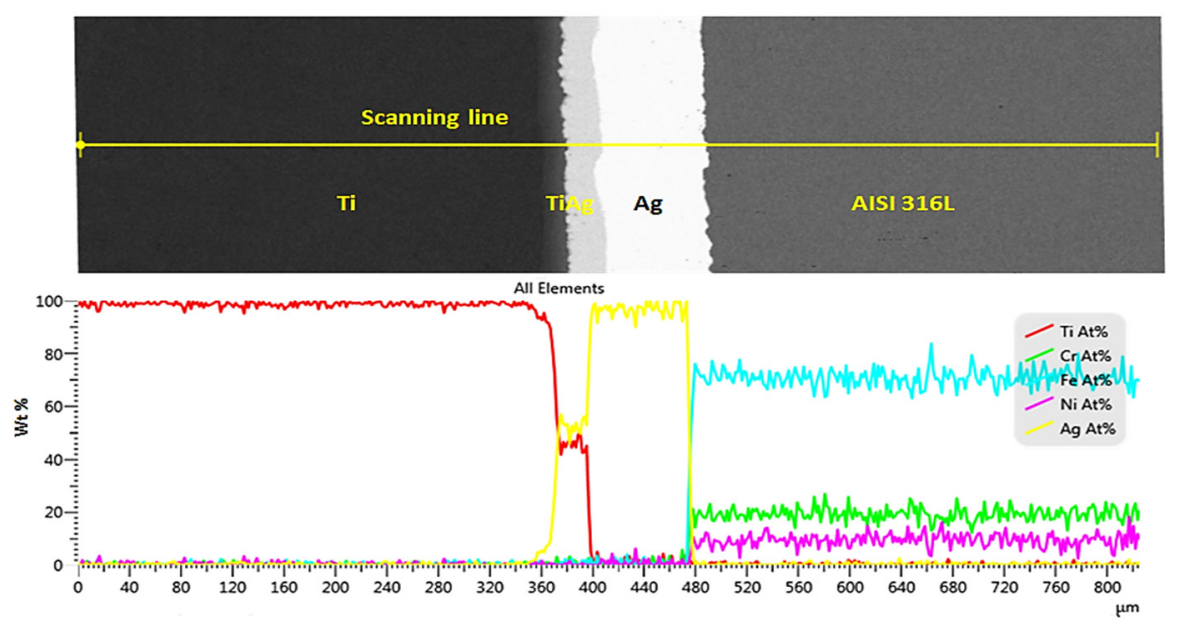

Fig. 2 SEM image and corresponding EDS scanning line of results for the bonded joint with $\mathrm{Ag}$ interlayer (Gleeble $-850^{\circ} \mathrm{C} ; 6 \mathrm{MPa} ; 20 \mathrm{~min}$ )

To verify such presumption, there was performed experiment where samples Ti-Ag-SS were firstly diffusively bonded at device Gleegle 3500 at temperature $850^{\circ} \mathrm{C}$, pressure $6 \mathrm{MPa}$ and holding time on temperature $20 \mathrm{~min}$. After cooling and unloading from Gleeble, samples were inserted into vacuum furnace for holding time of $10 \mathrm{hrs}$ at temperature $850^{\circ} \mathrm{C}$. The aim of experiment was to verify, whether there would be at least partial diffusion of $\mathrm{Ag}$ into material AISI 316L. Moreover, there was effort to determine diffusion rate of Ag into titanium. Results of experiments are shown in Fig. 3. It is obvious that high holding time at temperature $850^{\circ} \mathrm{C}$ resulted in fractures on the TiAg-Ag interface. They are (despite the high ductility of Ag interlayer) probably caused by differences between thermal expansion coefficients for titanium and silver. Furthermore, there was proved that even under 10-times extension of holding time, there isn't diffusion of Ag interlayer into steel AISI 316L. Thus there's no need to find or optimize diffusion welding process parameters for Ag interlayer.

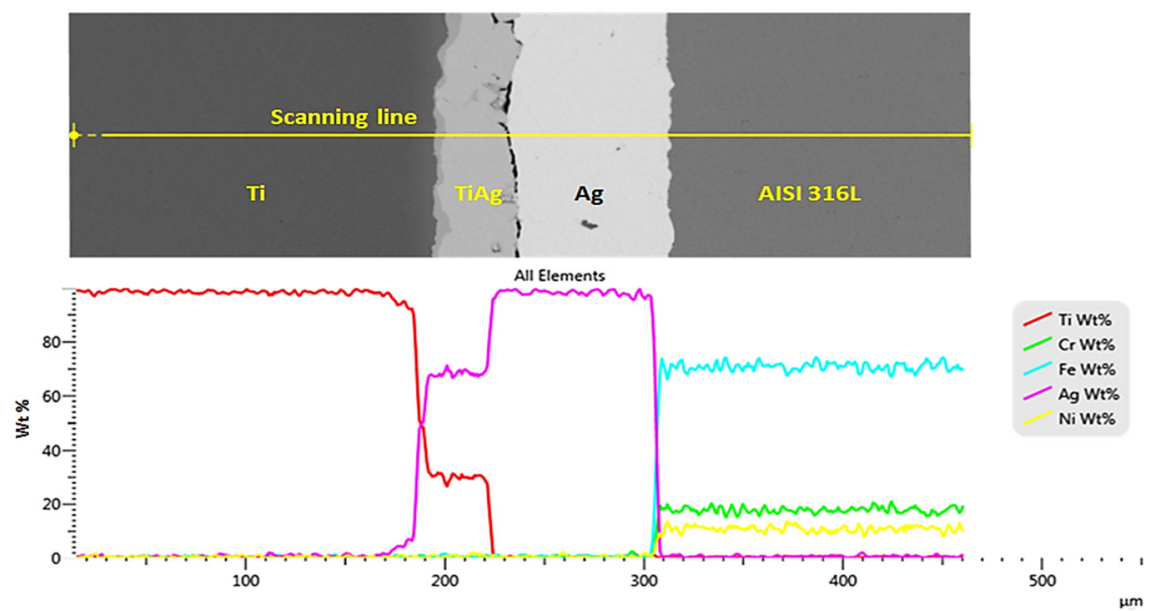

Fig. 3 SEM image with EDS scanning line scanning of results for the bonded joint with Ag interlayer (Gleeble $-850^{\circ} \mathrm{C} ; 6 \mathrm{MPa} ; 20 \mathrm{~min}$ ) and $10 \mathrm{hrs}$ in vacuum furnace at temperature $850^{\circ} \mathrm{C}$ 
As another recommended type of interlayer for combination Ti-SS there is $\mathrm{Cu}$ interlayer. This problems is solved e.g. by S. Kundu and his colleagues at bonding the commercially pure Ti Gr 2 and AISI 304 steel. $\mathrm{Cu}$ interlayer reveals good result on final welded joint in view of ductility [8]. Therefore, it is anticipated that $\mathrm{Cu}$ can be estimated as a potential candidate to be used as interlayer to improve the joint ductility. S. Kundu performed the diffusion welding with $\mathrm{Cu}$ interlayer for temperatures 850 up to $950^{\circ} \mathrm{C}$, pressure $3 \mathrm{MPa}$ and holding time $90 \mathrm{~min}$. Based upon the experiments, he states that at temperatures $900^{\circ} \mathrm{C}$ and higher, $\mathrm{Cu}$ interlayer can't stop diffusion of $\mathrm{Fe}, \mathrm{Cr}$ and $\mathrm{Ni}$ into $\mathrm{Ti}$ and reversely $\mathrm{Ti}$ into SS. That is why there are created brittle IMC's in diffusion area, which have a crucial influence on increase of hardness and brittleness in the joint area. Because of that, there was decided to carry out experiment with $\mathrm{Cu}$ interlayer at temperature $850^{\circ} \mathrm{C}$, pressure $3 \mathrm{MPa}$ and holding times 30, 60 and $90 \mathrm{~min}$.

There was only a partial diffusion and thus insufficient joint strength at temperature $850^{\circ} \mathrm{C}$ and holding time $30 \mathrm{~min}$. This result is shown in Fig. 4. There was joint failure in the $\mathrm{Cu}$ interlayer, when part of interlayer remained on the SS part (Fig. 4 - left) and part on the titanium part.
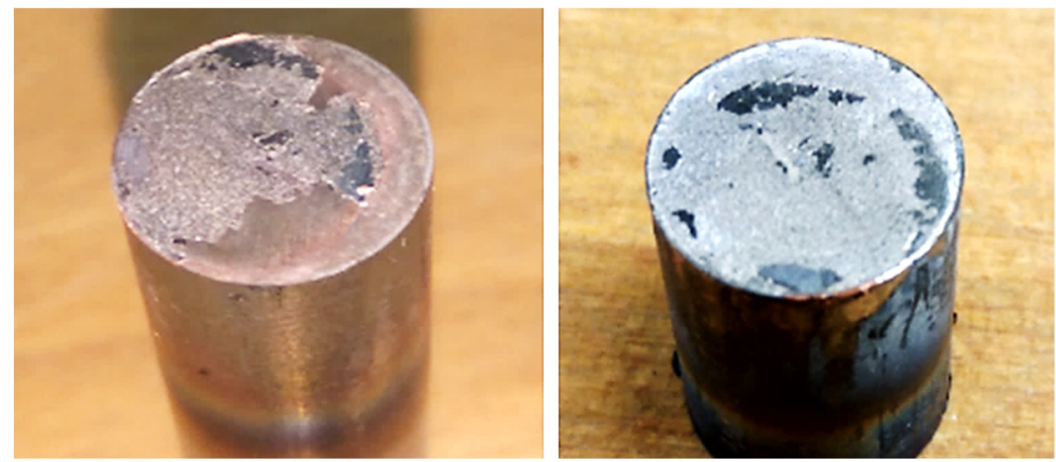

Fig. 4 Failure of $\mathrm{Cu}$ interlayer in sample SS-Cu-Ti after diffusion welding $\left(850^{\circ} \mathrm{C} ; 3 \mathrm{MPa} ; 30 \mathrm{~min}\right)$

As it can be seen from Fig. 5 (acquired by the optical microscope Olympus DSX 500) there was not achieve full diffusion bonding even after extension of holding time to $90 \mathrm{~min}$. Nevertheless, from the measurement of micro-hardness HV0.1 it is clear that in the weld joint are not created hard and brittle IMC's and total hardness HV0.1 didn't exceed magnitude 265 HV. To create full diffusion welding through the whole cross-section, there is necessary to extend diffusion time or increase diffusion activation energy by higher temperature. Based upon these facts, there was decided to apply another holding time at temperature $850^{\circ} \mathrm{C}$ in the vacuum furnace for sample diffusively welded by device Gleeble $\left(850^{\circ} \mathrm{C}, 3 \mathrm{MPa}, 90\right.$ min). To be specific, holding time at temperature $850^{\circ} \mathrm{C}$ was now $5 \mathrm{hrs}$.

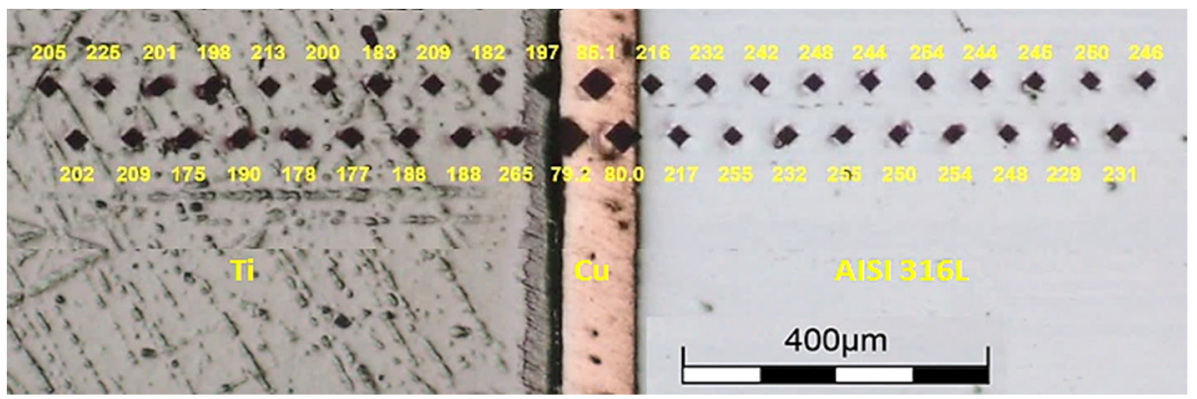

Fig. 5 Results of measurement micro-hardness HV0.1 on the sample with $\mathrm{Cu}$ interlayer (Gleeble $-850^{\circ} \mathrm{C}$; $3 \mathrm{MPa} ; 90 \mathrm{~min}$ ) 
From the result shown in Fig. 6, it is obvious that total diffusion time $6.5 \mathrm{hrs}$ at temperature $850^{\circ} \mathrm{C}$ is sufficient to create quality diffusion bonding through the whole crosssection both on the side of Ti and on the side of SS. However, used diffusion time was too long, because there is diffusion of Ti through the whole thickness of $\mathrm{Cu}$ interlayer $0.125 \mathrm{~mm}$ into SS and simultaneously there is diffusion of $\mathrm{Fe}, \mathrm{Cr}$ and $\mathrm{Ni}$ into Ti. Due to this fact there were created brittle IMC's, which not only increased micro-hardness HV0.1 up to $418 \mathrm{HV}$ (see Fig. 7), but also caused fractures creation on the boundary with steel AISI 316L.

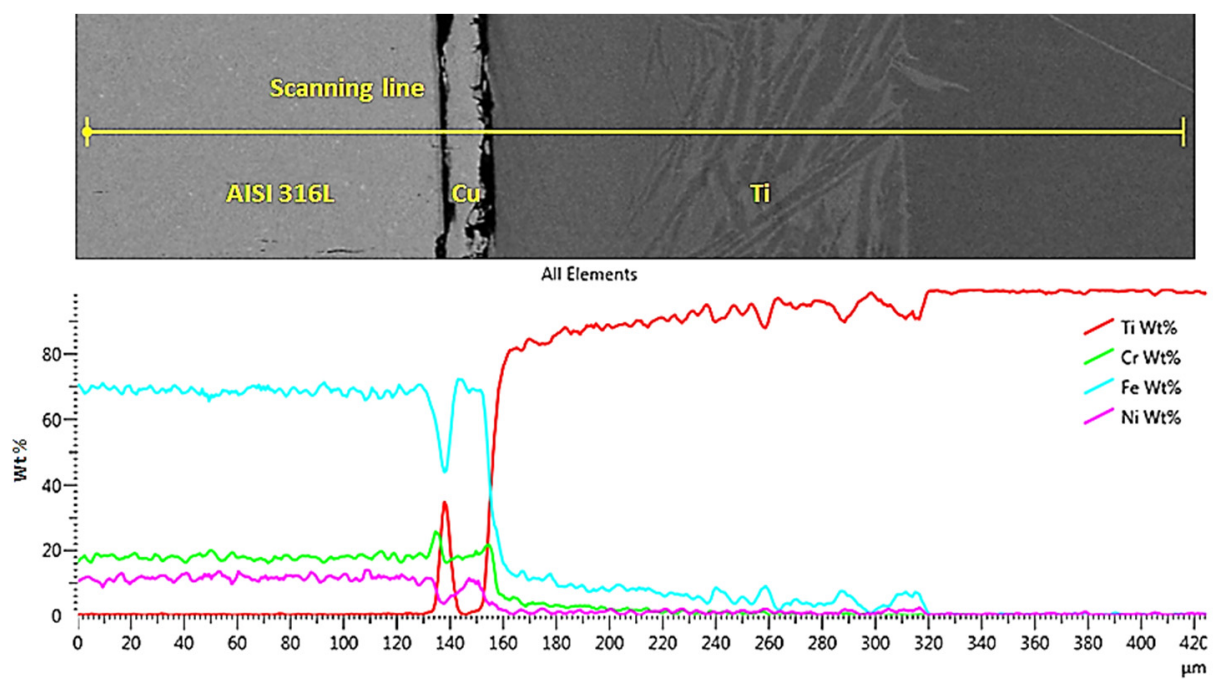

Fig. 6 SEM image and relevant EDS scanning line of results for the bonded joint with $\mathrm{Cu}$ interlayer (Gleeble $-850^{\circ} \mathrm{C} ; 3 \mathrm{MPa} ; 20 \mathrm{~min}$, vacuum furnace $850^{\circ} \mathrm{C} ; 300 \mathrm{~min}$ )

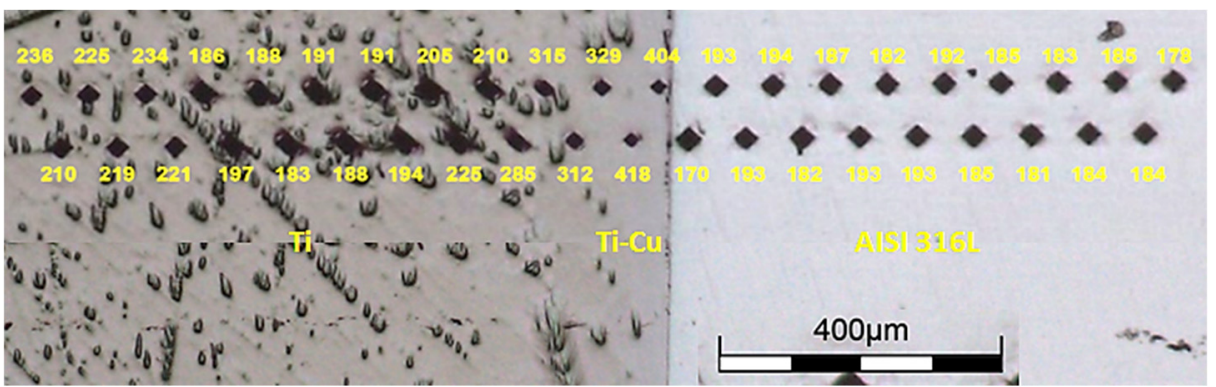

Fig. 7 Results of measurement micro-hardness $\mathrm{HV} 0.1$ on the sample with $\mathrm{Cu}$ interlayer (Gleeble $-850^{\circ} \mathrm{C} ; 3 \mathrm{MPa} ; 20 \mathrm{~min}$, vacuum furnace $850^{\circ} \mathrm{C} ; 300 \mathrm{~min}$ )

\section{Conclusion}

Diffusion welding is quite progressive technology at production heterogeneous welds created in solid state. On the other hand, this technology has also its limitations - mainly at welding materials, which create brittle IMCs on the materials boundary during diffusion. As example of such joint there is joint Ti-Fe - eventually with other elements as $\mathrm{Cr}$, Al, etc.

One of the possibilities how to eliminate joint brittleness at diffusion welding there is usage of the metal interlayers. These interlayers have several objectives. $1^{\text {st }}$ of them is to create transient layer, which prevent connection of elements that create hard and brittle IMCs during diffusion. Therewithal it should be valid for these interlayers that they have at least 
partial solubility in solid state with the welding materials and also that they do not create own brittle IMCs with these materials and their major alloying elements.

In the paper were described possibilities to use 3 types of metal interlayers $(\mathrm{Ni}, \mathrm{Ag}, \mathrm{Cu})$ at diffusion welding of pure titanium Gr 2 and austenitic highly alloyed steel AISI 316L. In light of requirements pose on theses interlayers it seems that Ni interlayer is the most suitable one. Nickel has very high diffusion resistance in comparison to majority of basic alloying elements. Thus there is diffusion only in very narrow surface layer of $\mathrm{Ni}$ and due to the low diffusion rate, there aren't generally created intermetallic phase $\mathrm{Ti}_{2} \mathrm{Ni}$, which creates up to $40 \mathrm{wt} \%$ of $\mathrm{Ti}$ in $\mathrm{Ni}$. On the other hand, nickel interlayer needs higher magnitudes of activation energy given by higher temperature that should be at least $1000^{\circ} \mathrm{C}$ for diffusion. However, titanium Gr 2 reveals very high amount of deformation already at $900^{\circ} \mathrm{C}$ and pressure $1 \mathrm{MPa}$. That is why it would be probably better to use this interlayer in alloyed alloys of Ti having higher strength under high temperatures.

The $2^{\text {nd }}$ tested interlayer was Ag one. This interlayer creates with Ti solid solution whose hardness doesn't exceed pure Ti hardness. However, the problem about utilization of such $\mathrm{Ag}$ interlayer is on the side of AISI $316 \mathrm{~L}$, because solubility of $\mathrm{Ag}$ with $\mathrm{Fe}, \mathrm{Cr}$ and $\mathrm{Ni}$ is almost on zero value at temperatures up to $1000^{\circ} \mathrm{C}$. That is why on the boundary of these materials isn't created any bonding or just adhesive bonding.

The last tested interlayer was $\mathrm{Cu}$ one. Copper has very good solubility in solid state both with $\mathrm{Ti}$ and also with major alloying elements of steel AISI 316L. Nevertheless, problem here is to determine proper holding time on temperature so that there is sufficient diffusion through the whole cross-section of bonded sample and at the same time to prevent diffusion of $\mathrm{Ti}, \mathrm{Fe}, \mathrm{Cr}$ and $\mathrm{Ni}$ through the whole $\mathrm{Cu}$ interlayer thickness. However, in this case can be possible to apply suitable technological precautions as can be e.g. to increase $\mathrm{Cu}$ interlayer thickness at least to range from 0.25 up to $0.3 \mathrm{~mm}$.

This publication was written at the Technical University of Liberec, Faculty of Mechanical Engineering with help of the institutional support KSP 117/2200.

\section{References}

1. N. F. Kazakov, Diffusion Bonding of Materials. Moscow: Mashinostroenie Publishers (1985)

2. W. D. Callister, jr., Materials Science and Engineering: an introduction. USA: John Wiley \& Sons, Inc. (2007)

3. J. Moravec, M. Dikovits, M. C. Beal, I. Novakova, R. Chandezon, J. Sobotka, Selection of the proper diffusion welding parameters for the heterogeneous joint Ti grade 2/AISI 316L. Manufacturing Technology, Vol. 17, Issue 2, pp. 231-237 (2017)

4. S. Kundu, S. Chatterjee, Effect of bonding temperature on interface microstructure and properties of titanium 304stainless steel diffusion bonded joints with Ni interlayer. Materials Science and Technology, Vol. 22, Issue 10, October 2006, pp. 1201-1207 (2006)

5. F. L. Wang, G. M. Sheng, Y. Q. Deng, Impulse pressuring diffusion bonding of titanium to 304 stainless steel using pure Ni interlayer. Rare Metals, Vol. 35, Issue 4, 1 April 2016, pp. 331-336 (2016)

6. Y. Deng, G. Sheng, Ch. Xu, Evaluation of the microstructure and mechanical properties of diffusion bonded joints of titanium to stainless steel with a pure silver interlayer. Materials and Design, Vol. 46, April 2013, pp. 84-87, (2013) 
7. Ag-Fe binary diagram, http://www.crct.polymtl.ca/fact/phase_diagram.php?file=AgFe.jpg\&dir=FTlite

8. S. Kundu, M. Ghosh, A. Laik, K. Bhanumurthy, G.B. Kale, S. Chatterjee, Diffusion bonding of commercially pure titanium to 304 stainless steel using copper interlayer. Materials Science and Engineering A, Vol. 407, Issue 1-2, 25 October 2005, pp. 154160 (2005)

9. Fe-Cu binary phase diagram, https://www.metallab.net/chemsoc/alloys.php?id=26 